\title{
Isolation of Polycyclic Aromatic Hydrocarbons (PAHs) From Water by C-18 and Clean-Up by XAD-2 Resin
}

\author{
Wagner R. Trevelin, Maria D. Landgraf, \\ Luiz H. Vidal and Maria O. O. Rezende* \\ Universidade de São Paulo, Instituto de Física e Quimica de São Carlos, \\ Departamento de Química e Física Molecular \\ Caixa Postal 369, 13.560 São Carlos , SP, Brasil
}

Received: october 21, 1991; march 23, 1992.

\begin{abstract}
Determinou-se a eficiência de extração e recuperação da fase C-18 para amostras de água destilada dopadas com 16 hidrocarbonetos policíclicos aromáticos (PAHs). Procedeu-se ao "clean-up" para os 16 PAHs que foi baseado na adsorção cromatográfica na resina XAD-2, seguido de eluição seletiva com metanol, n-pentano e acetato de etila. Deste modo separou-se a fração que contém PAHs que foi analisada por cromatografia gasosa capilar. Obteve-se boa recuperação $(81,1-96,2 \%)$ para os PAHs de alto peso molecular, usando-se $0.3 \mathrm{~g}$ de fase $\mathrm{C}-18$. O procedimento de "clean-up" na resina XAD-2 com a posterior eluição seletiva provou ser adequado para a separação dos interferentes polares.

The recovery efficiency of a C-18 phase is determined using distilled water samples containing organic pollutants and a clean-up procedure is developed for 16 polycyclic aromatic hydrocarbons (PAHs). It is based on adsorption chromatography on XAD-2 resin and stepwise elution with metanol, n-pentane and ethyl acetate. The PAH fraction in water is isolated by this method and determined by capilary gas chromatography. The efficiency of group isolation is demonstrated with a mixture of 16 PAHs, hydrocarbons $\left(\mathrm{C}_{15}-\mathrm{C}_{20}\right), 2$,6-dimethylphenol, 1-octanol, 2-octanone and 2,6-dimethylaniline. Good recoveries were obtained for higher molecular weight PAHs $(81.1-96,2 \%)$ by using $0.3 \mathrm{~g}$ of the C-18 phase. Clean-up by a XAD-2 resin provided clean PAHs with total elimination of polar and non-polar organic contaminants.
\end{abstract}

Key Words: aromatic hydrocarbons; $P A H ; X A D-2$ resin.

\section{Introduction}

Polycyclic aromatic hydrocarbons (PAHs) constitute a class of organic compounds named "unambiguous priority pollutants" by the US Environmental Protection Agency $(E P A)^{1}$. This class of compounds has been shown to contain several potent carcinogens ${ }^{2}$.

Identification and quantification studies of this class of compounds in water matrices are necessary for solving several environmental problems arising from their biologic activity. The dificulty is to find an adequate support that could be used to pre-concentrate and isolate such compounds in order to minimize matrix interferences.

In fact, bonded phase silica is widely used to pre-concentrate organic compounds in natural waters ${ }^{3-9}$. A large variety of these supports chemically bonded to silica allow the choice of the more efficient sorbent in the particular application of interest ${ }^{10-12}$. An accurate determination of PAHs requires an eficient separation from polar and non-polar compounds that exist in large concentrations in natural waters. Thus, some methods like gel silica cromatography, sephadex LH-20 ${ }^{13}$ and thin layer chromatography ${ }^{14}$ have been used. XAD-2 resin, due the large quantity of aromatics, can strongly adsorb PAHs ${ }^{15}$.

In this work we investigated the performance of $\mathrm{C}-18$ phase (octadecylsilane) to concentrate 16 PAHs and XAD-2 resin (DVB-styrene copolymer) to separate them from other polar and non-polar organic pollutants in water.

\section{Materials and Methods}

Reagents and standards

A stock solution was prepared from PAHs, n-alkanes and polar organic compounds. This stock solution was prepared from a naphatalene, acenaphthylene, acenaphthene, fluorene, phenanthrene, anthracene, fluorathene, pyrene, benzo[a]anthracene, crysene, benzo[b]fluoranthene, benzo[k]fluoranthene, benzo[a]pyrene, dibenzo[a,h]anthracene, benzo[ghi] perylene and indeno[1,2,3-cd]pyrene (Supelco Bellfonte, PA, USA) mixture with nominal concentrations of $2000 \mathrm{ppm}$ in benzene/methyl chloride $(1: 1 \mathrm{v} / \mathrm{v})$ and from another stock solution of n-alkanes $\left(\mathrm{C}_{15}\right.$, $\mathrm{C}_{16}, \mathrm{C}_{17}, \mathrm{C}_{18}$ and $\mathrm{C}_{20}$ ), 2,6 dimethyphenol, 1-octanol, 2-oc- 
tanone and 2,6 dimethylaniline (Supelco, Bellefonte, PA, USA) at the $500 \mathrm{ppm}$ level in methyl chloride. Further dilutions were made with methanol (Merck) using a Hamilton Syringe $(100 \mu \mathrm{l})$ with final concentrations of $5 \mathrm{ppm}$ each.

Solvents were glass-distilled through a column $150 \mathrm{~cm}$ long. Water was purified in Milli-Q Purifier System (Millipore). XAD-2 (Rohm and Hass Company) of particle size 20-50 mesh and C-18 phase (Sigma Chemical Company) of particle size $40-63 \mu \mathrm{m}$ were purified by sequential soxhlet extractions with methanol for $8 \mathrm{~h}$, acetonitrile for $8 \mathrm{~h}$ and ethyl acetate for $8 \mathrm{~h}$.

\section{Sample preparation}

A micro-column $5.0 \mathrm{~cm}$ long and $0.5 \mathrm{~cm}$ I.D. was filled with $\mathrm{C}-18$ phase in different weights. It was then conditioned with $1 \mathrm{ml}$ of methanol followed by $5 \mathrm{ml}$ of distilled water. $1 \mathrm{ml}$ of the stock solution (PAHs, n-alkanes and polar organic compounds) at concentrations of $5 \mathrm{ppm}$ was diluted to $1000 \mathrm{ml}$ of water (5 ppb each compound) and perylene was used as internal standard. This solution was passed through the micro-column and its flow rate was adjusted to $30 \mathrm{ml} / \mathrm{min}$ by a peristaltic pump (HP $89052 \mathrm{~A}$ ). After the adsorption the column was dried with nitrogen gas at $40{ }^{\circ} \mathrm{C}$. The adsorbed material was eluted with $2 \mathrm{ml}$ of ethyl acetate allowing an equilibrium period of $60 \mathrm{~s}$ between the solvent and the $\mathrm{C}-18$ phase. A glass column of $0.5 \mathrm{~cm}$ I.D. was filled with $1.25 \mathrm{~g}$ of XAD-2 resin to a height of $9 \mathrm{~cm}$. A solvent reservoir was placed on top of the column. The eluted material from the $\mathrm{C}-18$ was transferred quantitatively to the top of resin bed. The column was then eluted successively with $5 \mathrm{ml}$ portions of methanol (polar fraction), $5 \mathrm{ml}$ of $\mathrm{n}$-pentane (non-polar fraction) followed by $10 \mathrm{ml}$ of ethyl acetate (PAH fraction). Solvent flow rate was adjusted to $3 \mathrm{ml} / \mathrm{min}$. Finally, a further volume of 10 $\mathrm{ml}$ of ethyl acetate was passed through the column, followed by $15 \mathrm{ml}$ of ethanol. The column was then ready for the next sample.
The fractions were evaporated to $0.5 \mathrm{ml}$ and analysed by high resolution gas chromatography (HRGC).

\section{Gas Chromatography}

Extracts were analysed on a HP 5890 gas chromatograph, equipped with a flame ionization detector and a HP Ultra-1 column ( $25 \mathrm{~m} \times 0,32 \mathrm{~mm}$ I.D., WCOT), with $0.17 \mu \mathrm{m}$ thick film. The oven temperature was programmed from 100 to $280^{\circ} \mathrm{C}$ at $5^{\circ} \mathrm{C} /$ minute during each chromatographic run.

\section{Results and Discussion}

Good recoveries of most of the sixteen PAHs in water were obtained by using C-18 and perylene as internal standard (Table 1).

Except for naphtalene and acenaphthylene, good recoveries were obtained for the higher molecular weight PAHs (81.1 - 96.2\%). The decrease recovery of lower molecular weight PAHs like napahthalene and acenaphthylene, $52.6 \%$ and $72.0 \%$, respectively, was atributed to losses during the drying step.

The use of a peristaltic pump brings some advantages such as the increasing of the reproducibility of the extraction method due its constant flow and an unlimited volume of sample can be eluted. However the small size of the particles of $\mathrm{C}-18$ phase causes a great compaction of them and over $0.3 \mathrm{~g}$ of $\mathrm{C}-18$ the peristaltic pump losses its capacity to elute the sample.

Isolation of $P A H S$

Desorption of organic compounds from XAD-2 resin in strongly influenced by the type of solvent. Table 2 lists the volumes of different solvents required for complete elution of non-polar compounds ( $\mathrm{n}$-alkanes, $\mathrm{C}_{15}-\mathrm{C}_{18}$ and $\mathrm{C}_{20}$ ), polar compounds (2,6-dimethylphenol, 2,6-dimethylaniline, 1-octanol and 2- octanone) and PAHs at $5 \mu \mathrm{g}$ level of each compound.

Table 1. Recoveries of Polycyclic Aromatic Hydrocarbons by using different weights of C-18 phase.

\begin{tabular}{rlrrr}
\hline peak & compound & \multicolumn{3}{c}{ Recovery (\%)* } \\
\hline & & $0.12 \mathrm{~g}$ & $0.25 \mathrm{~g}$ & $0.3 \mathrm{~g}$ \\
\cline { 3 - 5 } 5 & naphtalene & 50.5 & 51.2 & 52.6 \\
7 & acenaphthylene & 67.4 & 69.6 & 72.0 \\
9 & acenaphthene & 69.3 & 70.6 & 87.2 \\
12 & pluorene & 67.7 & 75.1 & 81.1 \\
13 & anthracene & 64.4 & 88.5 & 85.3 \\
15 & fluoranthene & 48.6 & 79.9 & 86.0 \\
17 & pyrene & 54.5 & 87.4 & 88.9 \\
18 & benzo[a]anthracene & 53.9 & 88.2 & 84.6 \\
19 & crysene & 17.7 & 76.5 & 91.0 \\
20 & benzo[b]fluoranthene & 16.8 & 77.8 & 95.0 \\
21 & benzo[k]fluoranthene & 18.0 & 82.4 & 96.1 \\
22 & benzo[a]pyrene & 14.1 & 77.5 & 95.8 \\
23 & dibenzo[a,h]anthracene & 16.0 & 75.9 & 91.1 \\
24 & benzo[ghi]perylene & 15.8 & 78.8 & 96.2 \\
25 & indeno[1,2,3-cd]pyrene & 15.4 & 73.3 & 91.0 \\
& & 16.0 & 77.6 & 92.3
\end{tabular}

* each experiment was made in triplicate. 
These values were obtained by collecting $5 \mathrm{ml}$ portions from the column eluate and analysing by gas chromatography.

Table 2. Required volumes $(\mathrm{ml})$ for the complete desorption of classes of compounds from $X A D-2$.

\begin{tabular}{lccc}
\hline solvent & non-polar & polar & PAHs \\
\hline methanol & 50 & 10 & 50 \\
toluene & 5 & 5 & 5 \\
n-pentane & 5 & 10 & $50^{*}$ \\
ethyl acetate & 5 & 5 & 5 \\
\hline
\end{tabular}

* except for naphathalene, acenaphtylene and acenaphtene.

Methanol is a strong eluent for polar compounds and a weak one for $n$-alkanes and PAHs. For the elution of nonpolar and PAHs a large volume of methanol is necessary; $n$ pentane is a strong eluent for n-alkanes, but it shows unadequate results for lower molecular weight PAHs, such as naphthalene, acenaphthylene and acenaphthene; n-pentane shows good elution for these compounds. The same occurs with three ring PAHs, such as phenanthrene and antracene, but with less intensity.

Toluene and ethyl acetate are strong eluents and do not get any group separation on XAD-2 if they are use separately. Due to these difficulties, a clean-up with three different solvents was developed by using $5.0 \mathrm{ml}$ of methanol to eliminate polar compounds, $5.0 \mathrm{ml}$ of n-pentane to eliminate non-polar compounds and $10.0 \mathrm{ml}$ of ethyl acetate to eliminate PAHs.

Recovery eficiencies were tested by using reference mixtures with $5 \mu \mathrm{g}$ each of the sixteen PAHs and the other nine organic pollutants, by using external standardization. They are listed in Table 3. The chromatograms (Figures 1-4) were obtained by injection of $2.0 \mu \mathrm{l}$ aliquots on the gas chromatograph.
Table 3. Recoveries of polar, non-polar compounds and PAHs after clean-up on $X A D-2$.

\begin{tabular}{|c|c|c|c|}
\hline \multirow[t]{2}{*}{ Compound } & \multicolumn{3}{|c|}{ Recovery $(\%)^{*}$} \\
\hline & fraction 1 & fraction 2 & fraction 3 \\
\hline 2-octanone & 86.6 & 13.5 & - \\
\hline 1-octanol & 87.1 & 13.1 & - \\
\hline 2,6-dimethylphenol & 94.7 & 5.3 & - \\
\hline 2,6-dimethylaniline & 84.6 & 14.4 & - \\
\hline $\mathrm{C}_{15}$ & - & 100 & - \\
\hline $\mathrm{C}_{16}$ & - & 100 & - \\
\hline $\mathrm{C}_{17}$ & - & 100 & - \\
\hline $\mathrm{C}_{18}$ & - & 100 & - \\
\hline $\mathrm{C}_{20}$ & - & 100 & - \\
\hline naphtalene & - & 74.0 & 26.0 \\
\hline acenaphthylene & - & 41.0 & 59.0 \\
\hline acenaphthene & - & 20.0 & 80.0 \\
\hline fluorene & - & - & 100 \\
\hline phenanthrene & - & 10.0 & 90.0 \\
\hline anthracene & - & 11.0 & 89.0 \\
\hline fluoranthene & - & - & 100 \\
\hline pyrene & - & - & 100 \\
\hline benzo[a]anthracene & - & - & 100 \\
\hline crysene & - & - & 100 \\
\hline benzo[b]fluoranthene & - & - & 100 \\
\hline benzo[k]fluoranthene & - & - & 100 \\
\hline benzo[a]pyrene & - & - & 100 \\
\hline dibenzo[a,h]anthracene & - & - & 100 \\
\hline benzo[ghi]perylene & - & - & 100 \\
\hline indeno $[1,2,3$-cd]pyrene & - & - & 100 \\
\hline
\end{tabular}

* each experiment was made in triplicate.

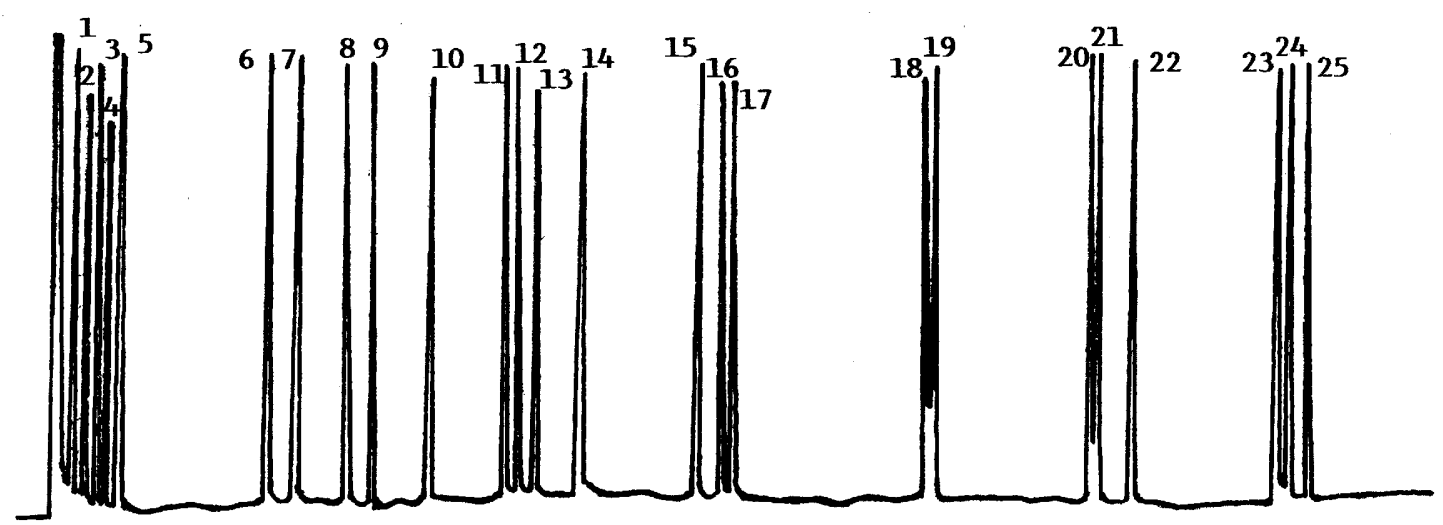

Figure 1. Gas chromatogram of all compounds studied.

1. 2-octane, 2. 1-octanol, 3. 2,6-dimethylphenol, 4.2,6-dimethylaniline, 5. naphtalene, 6. acenahthylene, 7. acenaphthene, 8. $C_{15}$, 9. fluorene, 10. $C_{16}, 11 . C_{17}$, 12. phenanthrene, 13. anthracene, 14. $C_{18}$ 15. fluoranthene, 16. $C_{2 a}$ 17. pyrene, 18. benzo[a]anthracene, 19. crysene, 20. benzo[b]fluoranthene, 21. benzo[k]fluoranthene, 22. bernzo[a]pyrene, 23. dizenbo[a, h] anthracene, 24. benzo[ghi]perylene, 25. indeno [1,2,3-cd]pyrene. 


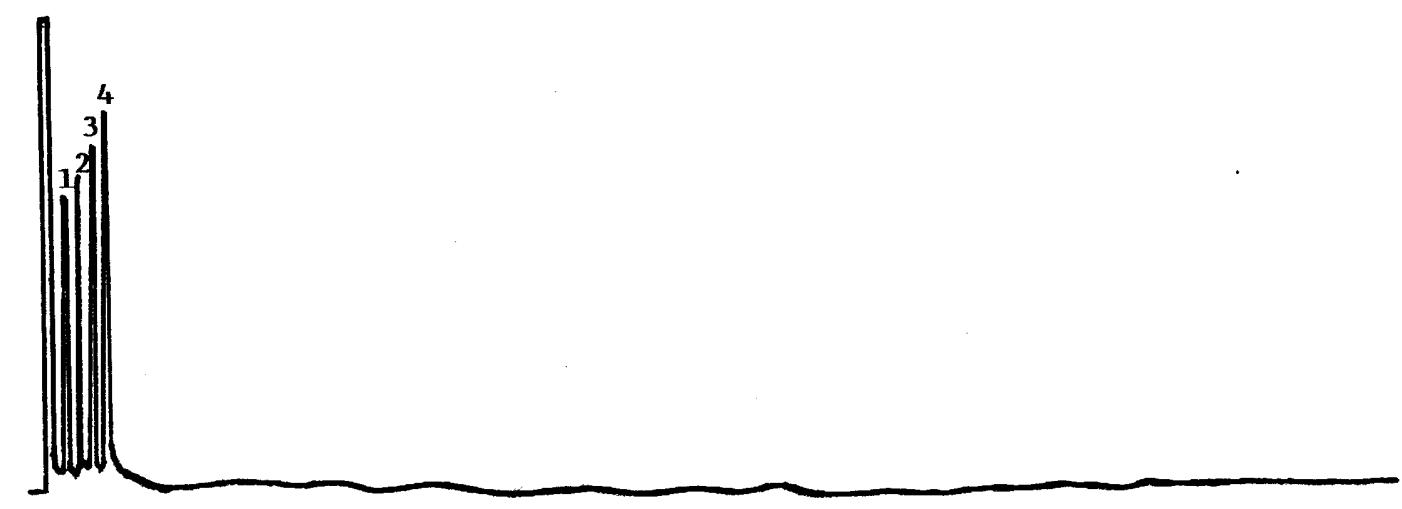

Figure 2. Gas chromatogram of polar fraction. 1. 2-octane, 2. 1-octanol, 3. 3,6-dimethylphenol, 4. 2,6-dimethylaniline.

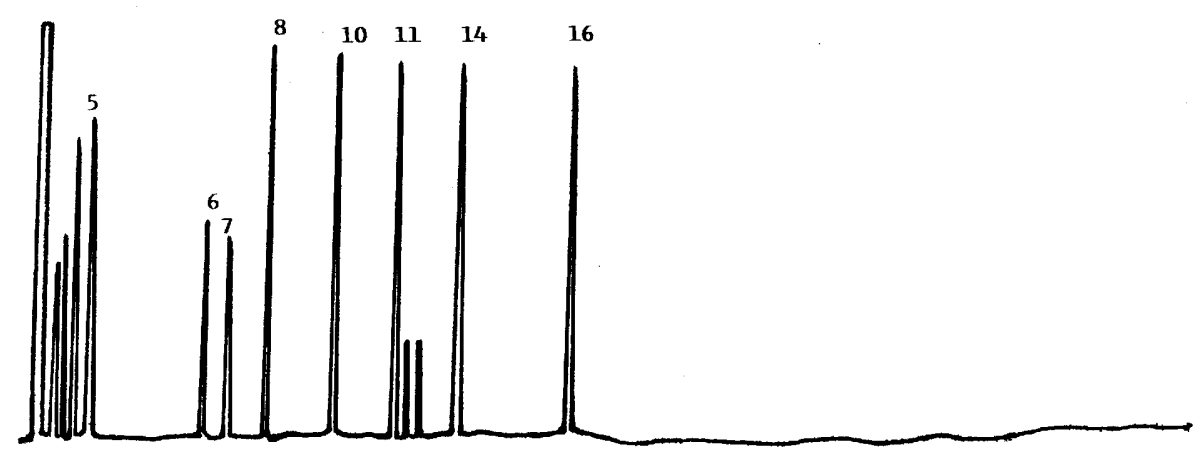

Figure 3. Gas chromatogram of the non-polar fraction. 5. naphthalene, 6. acenaphtylene, 7. acenaphthene, 8. $C_{15}, \quad$ 10. $C_{16}, \quad 11 . C_{17} \quad$ 14. $C_{18}, \quad$ 16. $C_{20}$

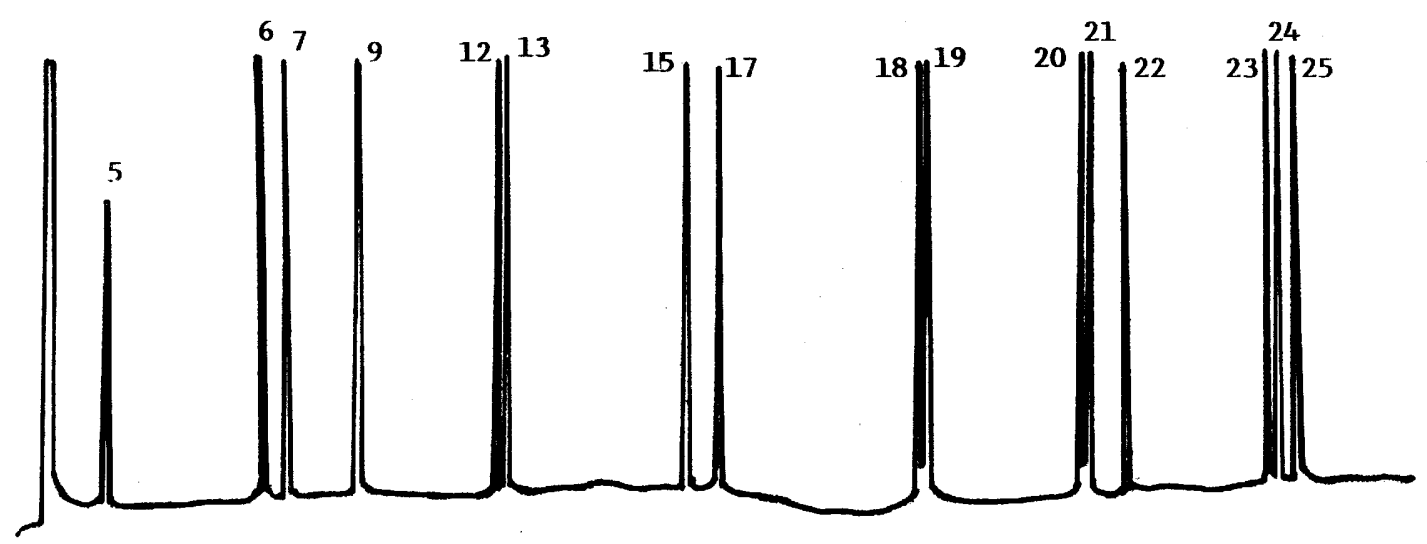

Figure 4. Gas chromatogram of the PAH fraction.

5. naphthalene, 6. acenaphtylene, 7. acenaphthene, 9. fluorene, 12. phenanthrene, 13. anthracene, 15. fluoranthene, 17. pyrene, 18. benzo[a]anthracene, 19. crysene, 20. benzo[b]fluoranthene,

21. benzo[k]fluoranthene, 22. bernzo[a]pyrene, 23. dibenzo[a,h]anthracene, 24. benzo[ghi]perylene,

25. indeno [1,2,3-cd]pyrene.

Figure 2 shows the elimination of polar compounds after elution with methanol. The total elimination of non-polar compounds after elution of n-pentane and parcial elimination of PAHs of two and three rings is shown in Figure 3. Clean-up by XAD-2 provided clean PAHs with total elimination of polar and non-polar organic contaminants (Figure 4).

\section{Conclusions}

The extraction of PAHs using C-18 phase showed good recoveries and further advantages compared with conventional solvent extraction methods. It was observed that the extraction step simultaneously involves the sample concentration, decreasing the preparation time and minimizing the background interferences due the adsorption and selective 
elution the sample. The extraction limit for PAHs was determined by the amount of the sample in the micro-column, since another solute present in large concentrations do no saturate the phase capacity.

The XAD-2 resin proved to be a good adsorbent for the separation of PAHs from polar and other non-polar organic contaminants from water matrices.

These factors improve the precision and accuracy of the analysis.

\section{Acknowledgments}

The authors thank FNNEP/PADCT and CNPq for financial support and Dr. Antonio Horácio Miguel for reading the manuscript.

\section{References}

1. Sampling and Analysis Procedures for Screening of Industrial Effluents for Priority Pollutants. U. S. Environmental Protection Agency, Environmental Monitoring an Support Laboratory, Cincinnati, Ohio, April (1977).

2. I.D. Brindle and X. F. Li, J. Chromatography, 498, 11-24 (1990).

3. E. Gruska. Bonded Stationary in Chromatography. Ann. Arbor Publishers. Ann. Arbor, M. I. (1978).

4. C.G. Creea. L. C. Simplifies, Isolating Organics from water. Res./Dev., 27, 40-4 (1976).

5. W. E. May, S. Schesler, S. Cram, B. Grump, H. Hertz, D. Enaconio and J. Dysisel, J. Chromatograph. Sci. 13, 535-40 (1975).

6. F.Eisenbeiss, H. Hein, E. Joester and G. Naundorf, Unit. Chem. Tech. 6, 8-12 (1977).

7. K. Ogan, E. Katz and W. Slavin, J. Chromatograph. Sci. 16, 517-22 (1978).

8. R. A. Dyler, D. L. Bodenner, K. J. Welch, R. J. Livkkonen, R. M. Carlson, H. L. Kopperman and R. Caple, Anal. Chem. 50, 837-42 (1978).

9. J.A. Graham and A. W. Garrison. Evaluation of Trace Enrichment Methodology in Conjunction with Reverse Phase HPLC for Pre-Concentration, Separation and Quantification of Trace Nonvolatile Organic Compound in Aqueous Environmental Samples. In Advances in the Identification \& Analysis of Organic Pollutants in Water, Vol. 1. L. H. Keith. Ed. Ann. Arbor Science Publishers, Ann Arbor. M. L., Chap. 26 (1981).

10. T.J. Good, Applications of Bonded Phase Materials. Am. Lab. 13(46), 36-8 (1981).

11. Method 525. Determination of Organic Compounds in Drinking Water by Liquid Solid Extraction and Capillary Column Gas Chromatography/Mass Spectrometry (Revision 2.1), Environment Monitoring System Laboratory, Office of Research and Development V. S. Environmental Protection Agency, Cincinatti, OH (1979).

12. National Primary Drinking Water Regulations: Analytical Techniques 40 CFR Parts 141 and 143 (Final Rule), Federal Register 53 (no. 33), $5142-5147$ (Feb. 19, 1988).

13. G. Grimer, J. Jacob and K. W. Naujack, J. Anal. Chem. 306-310 (1981).

14. J.M. Daisey and M. A. Leyko, Anal. Chem. 51, 24-28 (1979).
15. K.A. Kun and R. Kunin, J. Polym. Sci. 6, 2989-93 (1968). 